\title{
Bioelectrochemical hydrogen production with hydrogenophilic dechlorinating bacteria as electrocatalytic agents
}

\author{
Marianna Villano ${ }^{\mathrm{a}}$, Luca De Bonis ${ }^{\mathrm{a}}$, Simona Rossetti ${ }^{\mathrm{b}}$, Federico Aulenta ${ }^{\mathrm{a}}$, Mauro Majone ${ }^{\mathrm{a}, *}$ \\ a Department of Chemistry, Sapienza University of Rome, P.le Aldo Moro 5, 00185 Rome, Italy \\ ${ }^{\mathrm{b}}$ Water Research Institute (IRSA-CNR), National Research Council, Area della Ricerca Roma 1 Montelibretti, Via Salaria km. 29.300, 00015 Monterotondo (RM), Italy
}

\section{A R T I C L E I N F O}

\section{Article history:}

Received 11 June 2010

Received in revised form 6 October 2010

Accepted 7 October 2010

Available online 4 November 2010

\section{Keywords:}

Bioelectrochemical systems

Biocathode

Dechlorinating bacteria

Hydrogen production

Redox mediator

\begin{abstract}
A B S T R A C T
Hydrogenophilic dechlorinating bacteria were shown to catalyze $\mathrm{H}_{2}$ production by proton reduction, with electrodes serving as electron donors, either in the presence or in the absence of a redox mediator. In the presence of methyl viologen, Desulfitobacterium- and Dehalococcoides-enriched cultures produced $\mathrm{H}_{2}$ at rates as high as $12.4 \mu \mathrm{eq} / \mathrm{mgVSS}$ (volatile suspended solids)/d, with the cathode set at $-450 \mathrm{mV}$ vs. the standard hydrogen electrode (SHE), hence very close to the reversible $\mathrm{H}^{+} / \mathrm{H}_{2}$ potential value of $-414 \mathrm{mV}$ at $\mathrm{pH}$ 7. Notably, the Desulfitobacterium-enriched culture was capable of catalyzing $\mathrm{H}_{2}$ production without mediators at cathode potentials lower than $-700 \mathrm{mV}$. At $-750 \mathrm{mV}$, the $\mathrm{H}_{2}$ production rate with Desulfitobacterium spp. was $13.5 \mu \mathrm{eq} / \mathrm{mgVSS} / \mathrm{d}$ ( or $16 \mu \mathrm{eq} / \mathrm{cm}^{2} / \mathrm{d}$ ), nearly four times higher than that of the abiotic controls. Overall, this study suggests the possibility of employing dechlorinating bacteria as hydrogen catalysts in new energy technologies such as microbial electrolysis cells.
\end{abstract}

() 2010 Elsevier Ltd. All rights reserved.

\section{Introduction}

The production of hydrogen as energy source should ideally be based on renewable resources and sustainable processes (Turner, 2004). Microbial electrolysis cells (MEC) have the potential to replace conventional electrolytic systems operating with platinum or other precious metals. In a MEC "exoelectrogenic" microorganisms (Logan, 2009; Rabaey and Verstraete, 2005) oxidize (waste) organic matter by releasing electrons to a solid-state electrode (anode) and carbon dioxide and protons into solution. By applying a small external voltage to the system, electrons can be forced to travel from the anode to the cathode and combine with protons to produce molecular $\mathrm{H}_{2}$ (Logan et al., 2008). Typically, the equilibrium anode potential generated from the bacterial oxidation of organic substrates (e.g., acetate) is around $-300 \mathrm{mV}$ (vs. the standard hydrogen electrode, SHE). Under standard conditions and $\mathrm{pH} 7$, the reversible potential of $\mathrm{H}^{+} / \mathrm{H}_{2}$ is $-414 \mathrm{mV}$, and therefore, the minimum theoretical voltage that has to be applied in order to produce $\mathrm{H}_{2}$ at the cathode is $114 \mathrm{mV}$. This voltage is very low compared to the voltage necessary for conventional water electrolysis (i.e., 1.6$2.0 \mathrm{~V}$ ) (Zeng and Zhang, 2010).

Currently, a major limitation of the process is that noble metal (e.g., Pt-based) catalysts are typically used on the cathode to enhance the rate and efficiency of hydrogen production. These noble metal catalysts are expensive and susceptible to poisoning. Various

\footnotetext{
* Corresponding author. Tel.: +39 06 49913646; fax: +39 06490631.

E-mail address: mauro.majone@uniroma1.it (M. Majone).
}

non-noble materials have been also studied (Call et al., 2009), but they typically exhibit insufficient chemical stability and/or reactivity at neutral pH for efficient MEC operation (Daftsis et al., 2003; Highfield et al., 1999; Rabaey and Keller, 2008; Selembo et al., 2009).

Microbial biocathodes, in which microorganisms are the electrocatalytic agents of the desired cathodic reaction, are potential alternatives to chemical cathodes since they are inexpensive, self-regenerating and can operate under neutral $\mathrm{pH}$. Lojou et al. (2002) showed that a pure culture of Desulfovibrio vulgaris immobilized onto a carbon electrode could catalyze $\mathrm{H}_{2}$ production with methyl viologen $(\mathrm{MV})\left(E^{\circ \prime}=-446 \mathrm{mV}\right)$ as a redox mediator and Rozendal et al. (2008) tested a MEC with a mixed culture biocathode of unknown microbial composition which catalyzed $\mathrm{H}_{2}$ production likely via direct extracellular electron transfer. The occurrence of methanogens in the mixed culture was the main limiting factor which required the removal of bicarbonate from the medium to maintain acceptable $\mathrm{H}_{2}$ yields.

Based on our earlier findings that a dechlorinating culture released some $\mathrm{H}_{2}$ in the presence of excess MV, in addition to dechlorinating trichloroethene (TCE), as a strategy to dispose of an excess of reducing equivalents (Aulenta et al., 2008), we established TCE dechlorinating (Desulfitobacterium-enriched) and cis-DCE dechlorinating (Dehalococcoides-enriched) cultures to produce $\mathrm{H}_{2}$ in shortterm potentiostatic tests (i.e., $8 \mathrm{~h}$ ) either at $-450 \mathrm{mV}$ (vs. SHE) in the presence of MV concentrations ranging from 0 to $2.5 \mathrm{mM}$ or without exogenous redox mediators, at cathode potentials ranging from -650 to $-900 \mathrm{mV}$ (vs. SHE). 


\section{Methods}

\subsection{Microbial dechlorinating cultures}

The TCE dechlorinating and cis-DCE dechlorinating cultures were established by enrichment from contaminated sediments of the Venice Lagoon (Aulenta et al., 2002) and maintained in anaerobic bioreactors with a liquid volume of 1.4 and $0.6 \mathrm{~L}$ for the TCE dechlorinating and the cis-DCE dechlorinating culture, respectively. The reactors consisted of continuously stirred borosilicate glass bottles, sealed with a Teflon-faced butyl rubber stoppers and aluminum crimp seals. The bioreactors were operated at $25 \pm 1{ }^{\circ} \mathrm{C}$ in fill and draw mode. Every 7 days, they received a spike of neat trichloroethene (TCE) or cis-dichloroethene (cis-DCE) to a nominal concentration (i.e., neglecting the partitioning of compounds into the gas phase) of $0.5 \mathrm{mM}$. Thereafter, hydrogen gas $(99.5+\%)$ was added to the headspace of the reactors to a nominal concentration of 2.1 and $1.4 \mathrm{mM}$, for the TCE dechlorinating and the cis-DCE dechlorinating culture, respectively. Before each feeding, the headspace of each bioreactor was flushed with a $\mathrm{N}_{2} / \mathrm{CO}_{2}$ (70:30) gas mixture to remove all the volatile compounds. Weekly, a fixed volume of suspended culture was removed from each culture and replaced by anaerobic basal medium, which contained (g/L): $\mathrm{NH}_{4} \mathrm{Cl}, 0.5 ; \mathrm{MgCl}_{2} \cdot 6 \mathrm{H}_{2} \mathrm{O}, 0.1 ; \mathrm{K}_{2} \mathrm{HPO}_{4}, 0.4 ; \mathrm{CaCl}_{2} \cdot 2 \mathrm{H}_{2} \mathrm{O}$, $0.05 ; 10 \mathrm{~mL} / \mathrm{L}$ of a trace metal solution (Balch et al., 1979), $10 \mathrm{~mL} / \mathrm{L}$ of vitamin solution (Zeikus, 1977), and $15 \mathrm{~mL} / \mathrm{L}$ of $\mathrm{NaHCO}_{3}$ $(10 \% \mathrm{w} / \mathrm{v})$. The $\mathrm{pH}$ of the medium was 7.5 . For both cultures the average cell retention time was maintained at around 60 days. The pseudo steady-state biomass concentration was about $63 \mathrm{mgVSS} / \mathrm{L}$ for the TCE dechlorinating culture and about $53 \mathrm{mgVSS} / \mathrm{L}$ for the cis-DCE dechlorinating culture. During fill and draw cycles, TCE was predominantly dechlorinated to cis-DCE and, in lower amounts, also to vinyl chloride (VC) and ethene; in the other bioreactor, cis-DCE was predominantly dechlorinated to VC and lower amounts of ethene. The two bioreactors were operated for a period of over 3 years. Prior to the bioelectrochemical experiments, the microbial composition of the two cultures was analyzed by fluorescence in situ hybridization (FISH) and catalyzed reporter deposition (CARD)-FISH in order to quantify the relative abundance of the different dechlorinating bacteria as described previously (Fazi et al., 2008; Rossetti et al., 2008). Hybridizations with the specific probes DSF440 and DSF475 for Desulfitobacterium spp.; DHE1259t and DHE1259c for Dehalococcoides spp. were carried out simultaneously with DAPI and/or probes EUB338, EUB338-II, and EUB338-III combined in a mixture (EUB), specific for most Bacteria. Details on oligonucleotide probes are available at probeBase (Loy et al., 2007). The probes were synthesized with 5'-FITC and -Cy3 labels and purchased from MWG AG Biotech (Germany). The ratios of the cells binding the group-specific probes and of cells staining with DAPI or binding the EUB probes were established for at least 20 different, randomly selected fields. Images were captured with Olympus F-view CCD camera and handled with AnalySIS software (SIS, Munster, Germany).

\subsection{Bioelectrochemical cell setup}

The bioelectrochemical cell setup used in this study consisted of two gastight borosilicate glass bottles (with a total volume of about $270 \mathrm{~mL}$ per bottle) separated by a $3 \mathrm{~cm}^{2}$ cross-sectional area, Nafion $^{\circledR} 117$ proton exchange membrane (PEM). The PEM was boiled successively in $\mathrm{H}_{2} \mathrm{O}_{2}(3 \% \mathrm{v} / \mathrm{v})$, DI water, then in $0.5 \mathrm{M}$ $\mathrm{H}_{2} \mathrm{SO}_{4}$, and DI water each for $2 \mathrm{~h}$, and stored in DI water. The cathodes used were either a piece $(50 \times 10 \mathrm{~mm})$ of carbon paper (ETEK; nominal surface area $\sim 8 \mathrm{~cm}^{2}$ ) or a glassy carbon rod (HTW GambH, Germany; $5 \mathrm{~mm}$ diameter, $50 \mathrm{~mm}$ length, nominal surface area $\sim 8 \mathrm{~cm}^{2}$ ); the anode was a glassy carbon rod (HTW GambH, Germany; $5 \mathrm{~mm}$ diameter, $50 \mathrm{~mm}$ length, nominal surface area $\sim 8 \mathrm{~cm}^{2}$ ). The distance between the anode and cathode was around $10 \mathrm{~cm}$. The reference electrode (placed in the cathode chamber) was a $\mathrm{KCl}$ saturated $\mathrm{Ag} / \mathrm{AgCl}$ electrode $(+199 \mathrm{mV}$ vs. standard hydrogen electrode, SHE) (Amel S.r.l., Milan, Italy). Voltages are reported with respect to SHE. Electrochemical potentiostatic measurements and monitoring were performed using a Galvanostat/ Potentiostat Amel 551 (Milan, Italy).

\subsection{Bioelectrochemical experiments}

The cathode and anode compartments of the bioelectrochemical cell were anaerobically filled with $150 \mathrm{~mL}$ of the dechlorinating culture and $150 \mathrm{~mL}$ of mineral medium, respectively, and flushed with a $\mathrm{N}_{2} / \mathrm{CO}_{2}(70: 30 \mathrm{v} / \mathrm{v})$ gas mixture.

The bioelectrochemical cell was connected to the potentiostat and the cathode potential was set at the desired value. A set of batch experiments was carried out either in the absence or in the presence of methyl viologen (MV). In the latter case, appropriate volumes of a $100 \mathrm{mM}$ stock solution of MV were added to achieve concentrations of 0-2.5 mM. Each batch experiment lasted $8 \mathrm{~h}$ and at regular intervals (e.g., every $2 \mathrm{~h}$ ), gaseous samples were taken from the headspace of the compartments using gastight, samplelock Hamilton (Reno, NV) syringes, and 500 and $40 \mu \mathrm{L}$ samples were analyzed by gas-chromatography for hydrogen and methane, respectively. In parallel, control tests were performed under the same operating conditions in the absence of the microbial culture or the redox mediator. The bioelectrochemical reactor was maintained at $25^{\circ} \mathrm{C}$ in a water bath, under vigorous magnetic stirring to ensure that current generation was not substantially affected by mass transfer phenomena.

The cumulative electric charge $\left(\mu \mathrm{eq}_{i}\right)$ that was transferred at the electrodes was calculated by integrating the current $(A)$ over the period of electrode polarization. Cumulative reducing equivalents $\left(\mu \mathrm{eq}_{\mathrm{H}_{2}}\right.$ ) that were used for the formation of $\mathrm{H}_{2}$ were calculated from the measured amounts of $\mathrm{H}_{2}$, considering the corresponding molar conversion factor of $2 \mu \mathrm{eq} / \mu \mathrm{mol}$. Coulombic efficiency (CE) for $\mathrm{H}_{2}$ was accordingly calculated as CE $(\%)=\left(\mu \mathrm{eq}_{\mathrm{H}_{2}} / \mu \mathrm{eq}\right) \times 100$. The energy recovery was calculated as $\eta_{E}(\%)=W_{\mathrm{H}_{2}} / W_{\mathrm{IN}}$, where $W_{\mathrm{H}_{2}}=n_{\mathrm{H}_{2}} \times \Delta G_{\mathrm{H}_{2}}$ is the energy content $(\mathrm{kJ})$ of the produced $\mathrm{H}_{2}$, calculated from the total amount of $\mathrm{H}_{2}$ produced $\left(n_{\mathrm{H}_{2}}\right.$, mol) and the molar Gibbs free energy of $\mathrm{H}_{2}$ oxidation by oxygen to water $\left(\Delta G_{\mathrm{H}_{2}}=-237.1 \mathrm{~kJ} / \mathrm{mol}\right) ; W_{\mathrm{IN}}$ is the electricity input determined as $C_{\mathrm{P}} \times E_{\mathrm{APP}}$, where $C_{\mathrm{P}}$ is the total Coulombs calculated by integrating the current over time and $E_{\mathrm{APP}}$ is the hypothetical applied voltage. This latter value was calculated by assuming a hypothetical anode potential of $-0.150 \mathrm{~V}$, as typical of acetate-fed bioanodes.

\subsection{Analytical methods}

The concentration of microorganisms in the source culture reactor was determined as volatile suspended solids (VSS), according to standard methods (APHA, 1995). $\mathrm{H}_{2}$ was analyzed in a $500 \mu \mathrm{L}$ gaseous sample by a Trace Analytical TA3000R reduction gas detector (RGD) $\left(\mathrm{H}_{2}\right.$ detection limit is $0.02 \mathrm{ppmv}$ ) (Menlo Park, CA). The $\mathrm{H}_{2}$ level above the range of the RGD (i.e., $\sim 100$ ppmv) was quantified using a Varian 3400 (Lake Forest, CA, USA) gas-chromatograph (stainless-steel column packed with molecular sieve, Supelco, He carrier gas $18 \mathrm{~mL} / \mathrm{min}$; oven temperature $180^{\circ} \mathrm{C}$; thermal-conductivity detector (TCD) temperature $200{ }^{\circ} \mathrm{C}$ ) (Aulenta et al., 2005). Methane was analyzed by injecting $40 \mu \mathrm{L}$ of sample headspace (with a gas-tight Hamilton syringe) into a Varian (Lake Forest, CA, USA) 3400 gas chromatograph (GC; $2 \mathrm{~m} \times 2 \mathrm{~mm}$ glass column packed with $60 / 80$ mesh Carbopack B/1\% SP-1000, Supelco; He carrier gas at $18 \mathrm{~mL} / \mathrm{min}$; oven temperature at $50{ }^{\circ} \mathrm{C}$; flame ionization 
detector (FID) temperature $260{ }^{\circ} \mathrm{C}$ ). Headspace concentrations were converted to aqueous-phase concentrations using tabulated Henry's law constants (Gossett, 1987).

\subsection{Chemicals}

Hydrogen (99.5+\%) and all the other chemicals were purchased from Sigma-Aldrich (Milan, IT) (except where differently indicated). The chemicals used to prepare the mineral medium were of analytical grade and were used as received.

\section{Results and discussion}

3.1. Molecular characterization of the dechlorinating cultures used in the bioelectrochemical tests

Over $91.5 \%$ and $99.5 \%$ of the microorganisms stained by DAPI in the TCE dechlorinating and cis-DCE dechlorinating cultures, respectively, were also stained with the eubacterial probe EUB (Fig. 1). In the TCE dechlorinating culture, 83.0\% and 5.6\% of EUBpositive cells were stained with the FISH probes targeting Desulfitobacterium and Dehalococcoides species, respectively. In contrast, in the cis-DCE dechlorinating culture, Dehalococcoides spp. accounted for over $96 \%$ of bacterial cells (Fig. 1). FISH images of Desulfitobacterium spp. and Dehalococcoides spp. cells after hybridization with specific probes can be found in Supplementary material. These results clearly demonstrate that the long-term operation of the bioreactors with TCE and cis-DCE as the sole electron acceptors, and $\mathrm{H}_{2}$ as the sole electron donor, was highly effective in selecting for Desulfitobacterium spp. and Dehalococcoides spp., respectively. These findings are also consistent with Desulfitobacterium spp. being capable to dechlorinating TCE to cis-DCE, using $\mathrm{H}_{2}$ or other substrates as electron donors (Nonaka et al., 2006) and with Dehalococcoides spp. being the only isolated microorganism capable to dechlorinating cis-DCE and VC with $\mathrm{H}_{2}$ as the sole electron donor (Maymo-Gatell et al., 1997).

\subsection{Bioelectrochemical $\mathrm{H}_{2}$ production at $-450 \mathrm{mV}$ (vs. SHE) in the presence of methyl viologen (MV)}

Both dechlorinating cultures showed the ability to catalyze $\mathrm{H}_{2}$ production, with specific production rates showing a saturation dependency on the liquid phase MV concentration (Fig. 2). Under all the experimental conditions, methane was not detected in the headspace of the cell. Importantly, over the entire range of MV con-

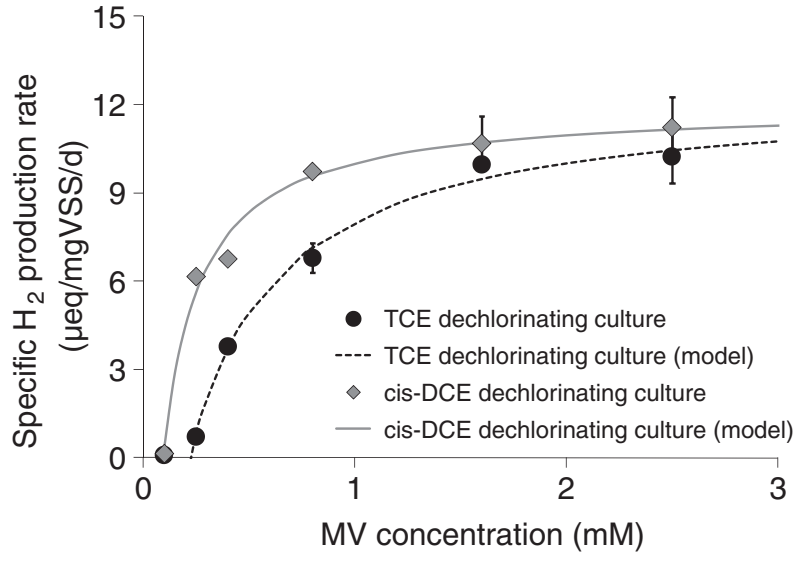

Fig. 2. Influence of methyl viologen (MV) concentration on $\mathrm{H}_{2}$ production rate by the microbial dechlorinating cultures in batch experiments at $-450 \mathrm{mV}$ (vs. SHE). For each culture, two MV concentration levels were assayed in duplicate (namely, 0.8 and $2.5 \mathrm{mM}$ for the TCE dechlorinating culture; 1.6 and $2.5 \mathrm{mM}$ for the cis-DCE dechlorinating culture); for these experiments the average value $( \pm 1$ standard deviation) of duplicates is reported. Lines are simulations based on MichaelisMenten model, modified to account for a MV threshold concentration.

centrations investigated, $\mathrm{H}_{2}$ production was negligible in abiotic (control) tests (data not shown).

Experimental data were fitted to a Michaelis-Menten-type model, modified to account for a MV threshold concentration (i.e., the lowest MV concentration which sustained a measurable $\mathrm{H}_{2}$ production) (Fennell and Gossett, 1998). Estimated maximum specific $\mathrm{H}_{2}$ production rates ( $k_{\mathrm{MAX}}$ ) were similar for the two cultures $(12.4 \pm 0.6 \mu \mathrm{eq} / \mathrm{mgVSS} / \mathrm{d}$ and $11.9 \pm 0.6 \mu \mathrm{eq} / \mathrm{mgVSS} / \mathrm{d}$, for the TCE and the cis-DCE dechlorinating culture, respectively). Conversely the half-velocity coefficients $\left(K_{\mathrm{m}}\right)$ and the MV threshold concentrations were substantially different, with the cis-DCE dechlorinating culture exhibiting a greater affinity for the mediator, namely a lower $K_{\mathrm{m}}(0.177 \pm 0.038 \mathrm{mM})$ and MV threshold concentration $(0.096 \pm 0.009 \mathrm{mM})$ than the TCE dechlorinating culture (estimated $K_{\mathrm{m}}$ and MV threshold concentration were $0.429 \pm 0.076$ and $0.222 \pm 0.016 \mathrm{mM}$, respectively).

The values of current densities, recorded during each test, almost linearly increased with the MV concentration, up to around $0.1 \mathrm{~mA} / \mathrm{cm}^{2}$ (at a mediator concentration of $2.5 \mathrm{mM}$ ), regardless the culture used.

For both cultures, the coulombic efficiency (CE), calculated at the end of the 8-h tests, reached a maximum value when MV

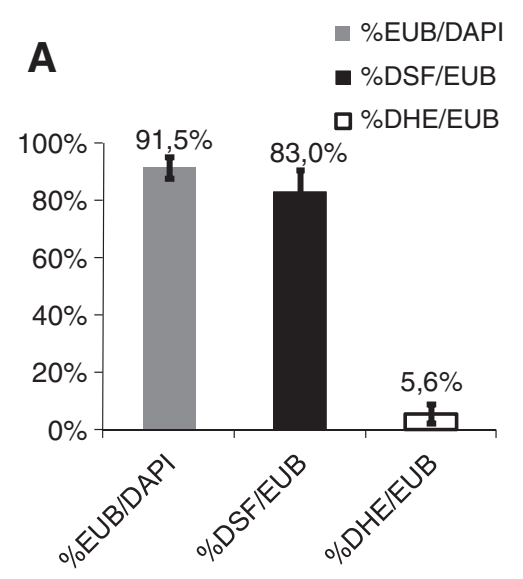

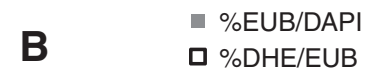

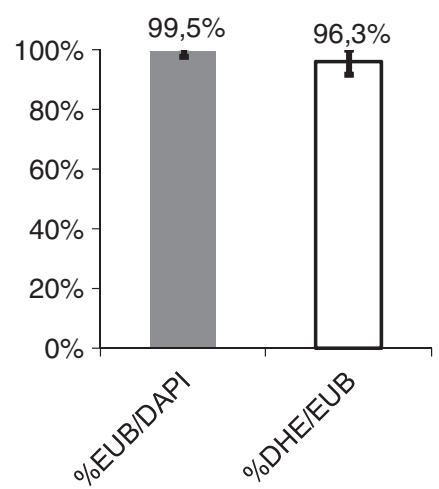

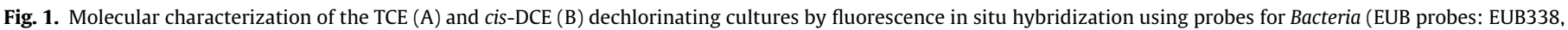

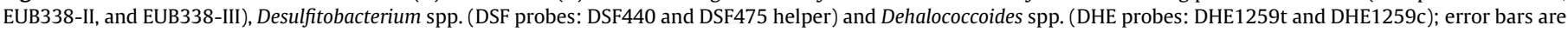
1 standard deviation of replicated measurements. 
was in the range $0.25-0.75 \mathrm{mM}$, then it gradually decreased as the MV concentration increased. Notably, the highest $C E$ values for the cis-DCE dechlorinating culture (i.e., over $40 \%$ at $0.25 \mathrm{mM}$ ) were typically higher than those observed with the TCE dechlorinating culture (i.e., around $25 \%$ at $0.75 \mathrm{mM}$ ). A possible explanation for the relatively low $C E$ values is the irreversible reduction of the radical $\mathrm{MV}^{+}$(i.e., the species thought to be involved in the electron transfer with the microorganisms) to $\mathrm{MV}^{0}$, as well as the formation of dimerization products from coupling reactions between $\mathrm{MV}^{+}$. radicals.

Regarding the mechanisms of $\mathrm{H}_{2}$ production in the presence of dissolved MV, it is worth noting that many dechlorinating bacteria, including Desulfitobacterium spp. and Dehalococcoides spp. possess multiple periplasmic hydrogenases which probably directly reacted with electrically reduced MV. A similar mechanism has been previously suggested for the sulfate-reducing bacterium Desulfovibrio vulgaris (Lojou et al., 2002).

\subsection{Bioelectrochemical $\mathrm{H}_{2}$ production in the absence of exogenous redox mediators}

Short-term (i.e., $8 \mathrm{~h}$ ) $\mathrm{H}_{2}$ production tests were also carried out in the absence of exogenous redox mediators, in a range of cathode potentials from -650 to $-900 \mathrm{mV}$. The aim of these tests was to explore the ability of the dechlorinating cultures to directly catalyze $\mathrm{H}_{2}$ production (via direct electron transfer) upon adsorption onto the surface of the polarized electrode. For these tests, carbon paper cathodes having a greater surface area than the glassy carbon cathodes (used in the tests with MV) were employed, in order to maximize bacterial adsorption onto the electrode surface.

Fig. 3 compares the time course of $\mathrm{H}_{2}$ production, with the cathode potential set at $-750 \mathrm{mV}$, for the two dechlorinating cultures and the abiotic control (from separate batch tests under identical experimental conditions). Differently from the tests carried out in the presence of soluble MV, the Desulfitobacterium-enriched culture showed a greater affinity for the cathode than the Dehalococcoides-enriched culture. The $\mathrm{H}_{2}$ production rate in the presence of the TCE dechlorinating (Desulfitobacterium-enriched) culture was nearly 3.7 times higher than in the abiotic control with a current density of $0.025 \mathrm{~mA} / \mathrm{cm}^{2}$; conversely the rate of $\mathrm{H}_{2}$ production in the presence of the cis-DCE dechlorinating (Dehalococcoides-enriched) culture was not significantly (95\% confidence) higher $(<40 \%)$, than that of the abiotic control despite the fact that the two cultures had a very similar cell concentration.

As expected, the specific rate (i.e., normalized with respect to the nominal surface area of the electrode) of $\mathrm{H}_{2}$ production increased with decreasing cathode potential (i.e., by setting the

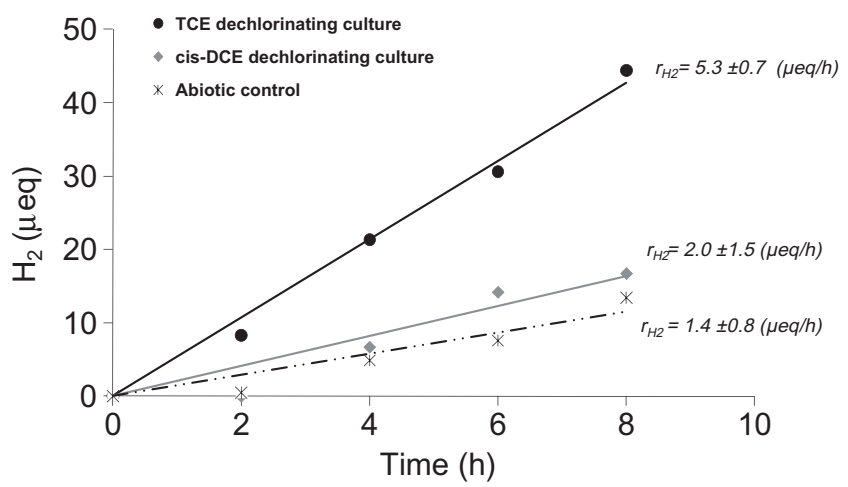

Fig. 3. $\mathrm{H}_{2}$ production without exogenous mediators by the dechlorinating cultures and the abiotic control: time course of produced $\mathrm{H}_{2}$ equivalents in batch experiments at $-750 \mathrm{mV}$ (vs. SHE). Calculated $\mathrm{H}_{2}$ production rates are average values ( \pm 1 standard deviation) of replicated experiments. cathode at more reducing potentials) in the biotic and abiotic tests (Fig. 4A). Notably, in the range of cathode potentials from -700 to $-900 \mathrm{mV}$, the specific rate of $\mathrm{H}_{2}$ production in the presence of the TCE dechlorinating culture was always higher than that measured in abiotic tests and hence purely due to electrochemical $\mathrm{H}^{+}$reduction. At $-900 \mathrm{mV}$ it reached a value of $329 \pm 36 \mu \mathrm{eq} / \mathrm{cm}^{2} / \mathrm{d}$ (or $278 \pm 31 \mu \mathrm{eq} / \mathrm{mgVSS} / \mathrm{d}$ ) with a current density of $0.44 \mathrm{~mA} / \mathrm{cm}^{2}$. In contrast, $\mathrm{H}_{2}$ production in the presence of the cis-DCE dechlorinating culture was almost indistinguishable from that measured in the abiotic control tests over the entire range of cathode potentials. These findings demonstrate the superior ability of Desulfitobacterium spp., compared to Dehalococcoides spp., to catalyze $\mathrm{H}_{2}$ production with solid electrodes serving as electron donors. Also in these tests, no methane was ever detected in the headspace of the cells.

The TCE dechlorinating culture did not only result in consistently higher $\mathrm{H}_{2}$ production rates than those of the abiotic controls, but also in higher $\mathrm{CE}$ and therefore reaction selectivity (Fig. 4B). Remarkably, the beneficial effect of the biocatalyst was greater at cathode potentials from -700 to $-800 \mathrm{mV}$ where the abiotic reaction was sluggish. As shown in Fig. 4, the CE approached 100\% for cathode potentials lower than $-800 \mathrm{mV}$ in the presence of the TCE dechlorinating culture as well as in abiotic controls.

For any given cathode potential, the contribution of bacterial catalysis to the rate of $\mathrm{H}_{2}$ production was calculated by subtracting the abiotic $\mathrm{H}_{2}$ production rate from the total biotic $\mathrm{H}_{2}$ production rate measured in the presence of the microbial culture. For the TCE dechlorinating culture, the $\mathrm{H}_{2}$ production due to bacterial catalysis accounted for at least $70 \%$ of the total $\mathrm{H}_{2}$ production at $-750 \mathrm{mV}$ (Fig. 5), and then gradually decreased at more negative cathode potentials where most of the $\mathrm{H}_{2}$ was derived from abiotic processes. At $-900 \mathrm{mV}$, less than $15 \%$ of the $\mathrm{H}_{2}$ was produced via bacterial catalysis (Fig. 5). It is also worth mentioning that, for
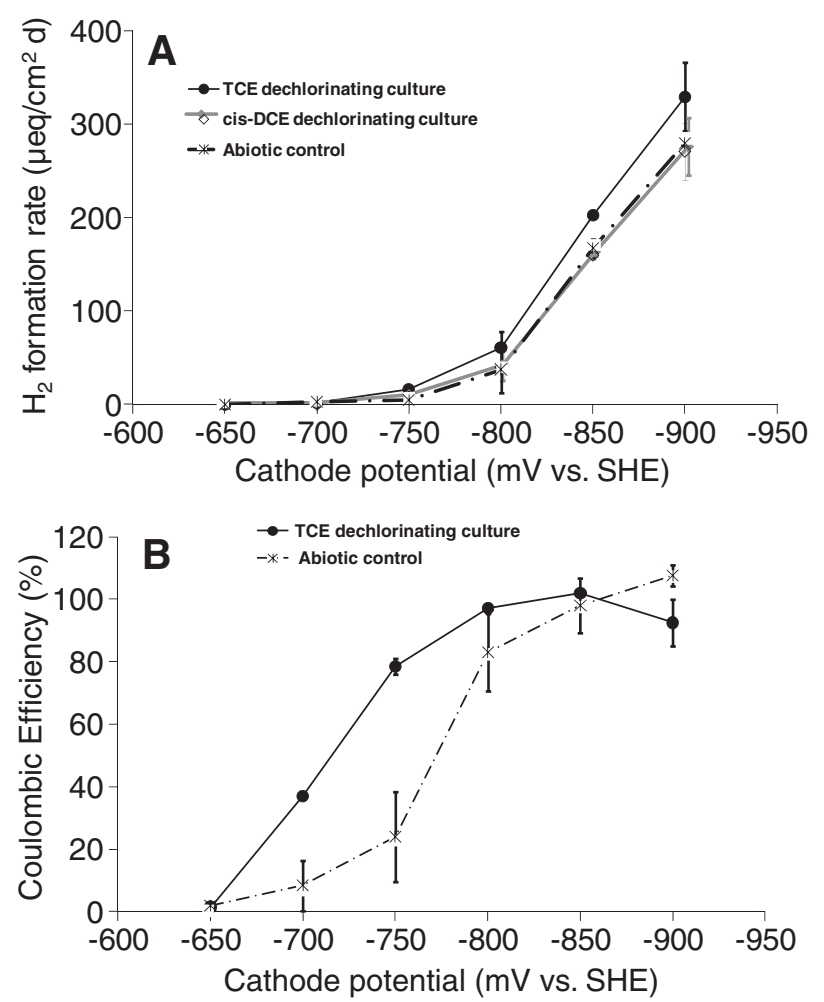

Fig. 4. Effect of cathode potentials on: (A) $\mathrm{H}_{2}$ production rate by the dechlorinating cultures and the abiotic control and (B) coulombic efficiency of $\mathrm{H}_{2}$ production by the TCE dechlorinating culture and the abiotic control. Error bars are 1 standard deviation of replicated tests. 
the TCE dechlorinating culture, the net biocatalytic $\mathrm{H}_{2}$ formation rate almost linearly increased with decreasing cathode potential and accordingly by increasing the driving force for the electron transfer (Fig. 5). The latter observation suggests that the rate of electron transfer from the electrode to the microorganisms, rather than the intrinsic biocatalyst activity, was limiting the rate of hydrogen production.

The mechanisms of $\mathrm{H}_{2}$ production by the TCE dechlorinating culture in the absence of exogenous redox mediators could not be determined. A possible mechanism could have involved the direct interaction of adsorbed bacterial cells with the surface of the polarized electrode and routing of electrons to hydrogenases via redox active components (e.g., cytochromes) located on the outer membrane of the microorganism (Rosenbaum et al., 2011). This hypothesis is in agreement with the fact that the genome of Desulfitobacterium sp. encodes several c-type cytochromes (Nonaka et al., 2006) whereas the genome of Dehalococcoides strains does not (Seshadri et al., 2005). It cannot be excluded that self-produced soluble mediators and/or products of bacterial lysis (including hydrogenases) may have also contributed to the shuttling of electrons from the electrode to the microorganisms or may have catalyzed the $\mathrm{H}_{2}$ production themselves (Freguia et al., 2010; Marsili et al., 2008). Importantly, it should be noted that the enhancement of $\mathrm{H}_{2}$ production rate (with respect to the abiotic controls) was observed only with the TCE dechlorinating culture, but not with cisDCE dechlorinating culture, though the two cultures had a very similar cell concentration. This finding indicates that the mechanism of $\mathrm{H}_{2}$ production was specific to the TCE dechlorinating culture and likely ascribable to the presence of Desulfitobacterium species; however, further investigations are needed to shed light on this fundamental issue.

\subsection{Energetic analysis of mediated and mediatorless bioelectrochemical $\mathrm{H}_{2}$ production}

The use of MV allowed production of $\mathrm{H}_{2}$ at $-450 \mathrm{mV}$, a value that is very close to the reversible $\mathrm{H}^{+} / \mathrm{H}_{2}$ potential, whereas a potential more negative than $-700 \mathrm{mV}$ was needed if the redox mediator was lacking. In other words, the mediator reduced the overpotentials for $\mathrm{H}_{2}$ evolution by at least $300 \mathrm{mV}$, thereby potentially reducing the energy input to the $\mathrm{H}_{2}$-producing electrolyzer. A higher CE was typically obtained in the tests carried out in the absence of MV, thereby indicating a more efficient usage of the electric current. To account for these factors, we calculated the energy yield (i.e., the energy recovery as $\mathrm{H}_{2}$ relative to the electrical energy input) for the mediatorless and mediated $\mathrm{H}_{2}$ production. For this calculation we considered a hypothetical applied voltage for

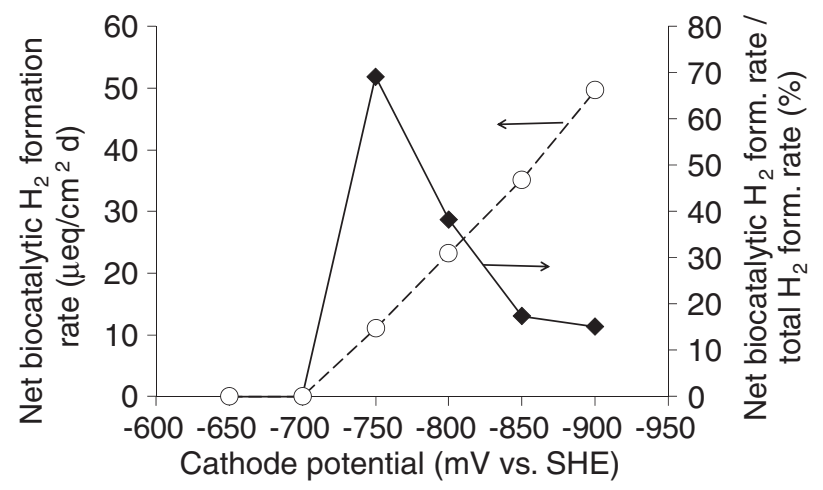

Fig. 5. Effect of cathode potential on the (net) rate of biocatalytic $\mathrm{H}_{2}$ production and on the relative contribution (\%) of the (net) rate of biocatalytic $\mathrm{H}_{2}$ production on the total $\mathrm{H}_{2}$ production rate by the microbial TCE dechlorinating culture. an electrolyzer or MEC having an anode potential of $-150 \mathrm{mV}$ [a value that is typical for acetate-fed MECs or MFCs (Aelterman et al., 2008)] and the different cathode configurations tested in this work (Fig. 6). For the tests carried out in the presence of different MV concentrations, only those yielding the highest energy yields are shown in Fig. 6 (i.e., $0.25 \mathrm{mM}$ for the cis-DCE dechlorinating culture and $0.75 \mathrm{mM}$ for the TCE dechlorinating culture). As shown in Fig. 6, in the presence of MV, the cis-DCE dechlorinating culture $(\mathrm{MV}=0.25 \mathrm{mM}$ ) resulted in a higher energy yield (about 170\%) than the TCE dechlorinating culture (about $100 \%$ with MV concentration of $0.75 \mathrm{mM}$ ). This fact reflects the relatively higher CE (over $40 \%$ ) obtained with the cis-DCE dechlorinating culture than the TCE dechlorinating culture at a relatively low hypothetical applied voltage $(300 \mathrm{mV})$ (i.e., with the cathode at $-450 \mathrm{mV})$. Similar energy yields were obtained in the absence of MV, with the highest value (over 180\%) observed in the presence of the TCE dechlorinating culture at a hypothetical applied voltage of $650 \mathrm{mV}$ (i.e., at a cathode potential of $-800 \mathrm{mV}$ ). These values of energy yield are comparable with those reported in the literature with metal catalysts (Call et al., 2009; Selembo et al., 2009; Tartakovsky et al., 2009).

Clearly, identification of the optimal biocathode conditions requires that other factors, besides energetic ones, are taken into consideration; these include the cost of the mediator (which is also function of its chemical and electrochemical stability under selected operating conditions) as well as the rate of $\mathrm{H}_{2}$ production needed. Along this line, it needs to be considered that the maximum volumetric $\mathrm{H}_{2}$ production rate in the presence of excess MV (e.g., $0.011 \mathrm{~m}^{3} / \mathrm{m}^{3} / \mathrm{d}$ for the TCE dechlorinating culture) was nearly the same than that obtained at $-750 \mathrm{mV}$ in the absence of MV (i.e., $0.010 \mathrm{~m}^{3} / \mathrm{m}^{3} / \mathrm{d}$, for the TCE dechlorinating culture), but much higher production rates were obtained in the absence of MV at more negative potentials.

It is expected that both for the mediated and the mediatorless biocathodes, $\mathrm{H}_{2}$ production rates could be greatly enhanced by increasing biomass density. The most appropriate strategies to achieve this will have to be identified in future investigations.

\subsection{Perspectives for application of hydrogenase-containing microorganisms in electrochemical systems}

In this study we have shown that living hydrogenophilic dechlorinating bacteria (i.e., Desulfitobacterium spp. and Dehalococcoides spp.), till now known for their ability to utilize hydrogen as an electron donor to respire chlorinated solvents (Holliger and Schumacher, 1994) can also carry out the reverse reaction of hydrogen generation (from water reduction), by using carbon-based

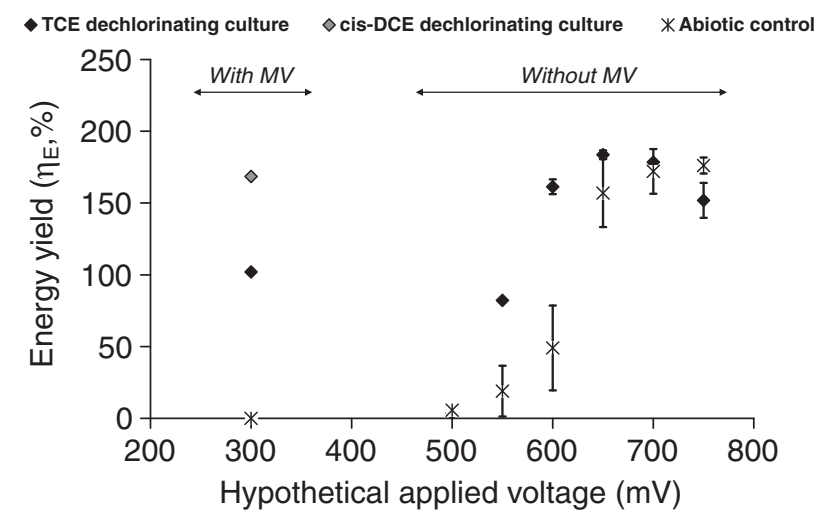

Fig. 6. Effect of hypothetical applied voltage on the energy recovery calculated as the ratio between the energy content of $\mathrm{H}_{2}$ produced and the electrical energy consumed (by arbitrarily assuming a value of the anode potential of $-150 \mathrm{mV}$ vs. SHE). Error bars are 1 standard deviation of replicated experiments. 
electrodes as electron donors. These dechlorinating bacteria are highly evolved to utilize $\mathrm{H}_{2}$ by means of multiple hydrogenase systems (Nonaka et al., 2006; Seshadri et al., 2005), which, most likely, are also involved in the observed bioelectrocatalytic activity toward $\mathrm{H}_{2}$ generation. Hydrogenases, the enzymes catalyzing the rapid interconversion of hydrogen and water in the microbial hydrogen cycle (Baker et al., 2009; Cracknell et al., 2008; Vincent et al., 2007) are receiving considerable attentions as effective electrocatalysts for fuel cells and electrolyzers. On the other hand, their high costs of isolation, difficulties in attaching these delicate molecules onto electrodic surfaces while protecting their fragile active sites from inactivation, have greatly hampered their practical application (Armstrong et al., 2009; Fourmond et al., 2009). Here we demonstrate that whole cells of dechlorinating bacteria, thus far only considered for bioremediation applications (Lovley, 2001), hold a potential as "novel" hydrogen catalysts for possible applications in new energy technologies such as microbial electrolysis cells. Based on the results of this study, in the future other hydrogenase-possessing microorganisms should also be assayed for similar applications. In this context, autotrophic microorganisms which do not rely on organic carbon for growth hold a significant potential. Nonetheless, further studies will also have to evaluate whether the bioelectrocatalytic $\mathrm{H}_{2}$ production is linked to energy conservation and microbial growth. This issue will have direct and practical implications on the long-term process durability and sustainability.

\section{Conclusions}

In a bioelectrochemical system, a Desulfitobacterium-enriched culture and a Dehalococcoides-enriched culture catalyzed $\mathrm{H}_{2}$ production with a carbon-based cathode set at $-450 \mathrm{mV}$ (a value that is very close to the reversible $\mathrm{H}^{+} / \mathrm{H}_{2}$ potential of $-414 \mathrm{mV}$ ), provided a soluble mediator (i.e., MV) was present in the solution.

Notably, the Desulfitobacterium-enriched culture was also capable to produce $\mathrm{H}_{2}$ in the absence of exogenous redox mediators, when the cathode was set at potentials more negative than $-700 \mathrm{mV}$. This suggests that the different dechlorinating microorganisms employ different mechanisms for routing electrons to hydrogenases, which will necessarily have to be identified in order to fully exploit their potential.

\section{Acknowledgements}

This study was carried out in the frame of the FITOLISI research project, funded by the Italian Ministry of Agriculture, Food, and Forestry (MIPAAF). The authors thank Prof. Stefania Panero, Dr. Priscilla Reale, and Dr. Judith Serra Moreno (Sapienza University of Rome) for their suggestions and comments with the experimental setup.

\section{Appendix A. Supplementary data}

Supplementary data associated with this article can be found, in the online version, at doi:10.1016/j.biortech.2010.10.146.

\section{References}

Aelterman, P., Freguia, S., Keller, J., Verstraete, W., Rabaey, K., 2008. The anode potential regulates bacterial activity in microbial fuel cells. Appl. Microbiol. Biotechnol. 78 (3), 409-418.

APHA, 1995. Standard Methods for the Examination of Water and Wastewater. American Public Health Association, Washington, DC.

Armstrong, F.A., Belsey, N.A., Cracknell, J.A., Goldet, G., Parkin, A., Reisner, E., Vincent, K.A., Wait, A.F., 2009. Dynamic electrochemical investigations of hydrogen oxidation and production by enzymes and implications for future technology. Chem. Soc. Rev. 38 (1), 36-51.
Aulenta, F., Majone, M., Verbo, P., Tandoi, V., 2002. Complete dechlorination of tetrachloroethene to ethene in presence of methanogenesis and acetogenesis by an anaerobic sediment microcosm. Biodegradation 13 (6), 411-424.

Aulenta, F., Gossett, J.M., Papini, M.P., Rossetti, S., Majone, M., 2005. Comparative study of methanol, butyrate, and hydrogen as electron donors for long-term dechlorination of tetrachloroethene in mixed anerobic cultures. Biotechnol. Bioeng. 91 (6), 743-753.

Aulenta, F., Canosa, A., Majone, M., Panero, S., Reale, P., Rossetti, S., 2008 Trichloroethene dechlorination and $\mathrm{H}_{2}$ evolution are alternative biological pathways of electric charge utilization by a dechlorinating culture in a bioelectrochemical system. Environ. Sci. Technol. 42 (16), 6185-6190.

Baker, S.E., Hopkins, R.C., Blanchette, C.D., Walsworth, V.L., Sumbad, R., Fischer, N.O. Kuhn, E.A., Coleman, M., Chromy, B.A., Létant, S.E., Hoeprich, P.D., Adams, M.W.W., Henderson, P.T., 2009. Hydrogen production by a hyperthermophilic membrane-bound hydrogenase in water-soluble nanolipoprotein particles. J. Am. Chem. Soc. 131 (22), 7508-7509.

Balch, W.E., Fox, G.E., Magrum, L.J., Woese, C.R., Wolfe, R.S., 1979. Methanogens: reevaluation of a unique biological group. Microbiol. Rev. 43 (2), 260-296.

Call, D.F., Merrill, M.D., Logan, B.E., 2009. High surface area stainless steel brushes as cathodes in microbial electrolysis cells. Environ. Sci. Technol. 43 (6), 21792183.

Cracknell, J.A., Vincent, K.A., Armstrong, F.A., 2008. Enzymes as working or inspirational electrocatalysts for fuel cells and electrolysis. Chem. Rev. 108 (7), 2439-2461

Daftsis, E., Pagalos, N., Jannakoudakis, A., Jannakoudakis, P., Theodoridou, E., Rashkov, R., Loukaytsheva, M., Atanassov, N., 2003. Preparation of a carbon fiber-nickel-type material and investigation of the electrocatalytic activity for the hydrogen evolution reaction. J. Electrochem. Soc. 150 (11), C787-C793.

Fazi, S., Aulenta, F., Majone, M., Rossetti, S., 2008. Improved quantification of Dehalococcoides species by fluorescent in situ hybridization and catalysed reporter deposition (CARD-FISH). Syst. Appl. Microbiol. 31 (1), 62-67.

Fennell, D.E., Gossett, J.M., 1998. Modeling the production of and competition for hydrogen in a dechlorinating culture. Environ. Sci. Technol. 32 (16), 2450-2460.

Fourmond, V., Lautier, T., Baffert, C., Leroux, F., Liebgott, P.P., Dementin, S., Rousset, M., Arnoux, P., Pignol, D., Meynial-Salles, I., Soucaille, P., Bertrand, P., Léger, C., 2009. Correcting for electrocatalyst desorption and inactivation in chronoamperometry experiments. Anal. Chem. 81 (8), 2962-2968.

Freguia, S., Tsujimura, S., Kano, K., 2010. Electron transfer pathways in microbial oxygen biocathodes. Electrochim. Acta 55 (3), 813-818.

Gossett, J.M., 1987. Measurement of Henry's law constants for C1 and C2 chlorinated hydrocarbons. Environ. Sci. Technol. 21 (2), 202-208.

Highfield, J.G., Claude, E., Oguro, K., 1999. Electrocatalytic synergism in Ni/Mo cathodes for hydrogen evolution in acid medium: a new model. Electrochim. Acta 44 (16), 2805-2814.

Holliger, C., Schumacher, W., 1994. Reductive dehalogenation as a respiratory process. Antonie Van Leeuwenhoek 66 (1-3), 239-246.

Logan, B.E., 2009. Exoelectrogenic bacteria that power microbial fuel cells. Nat. Rev. Microbiol. 7 (5), 375-381.

Logan, B.E., Call, D., Cheng, S., Hamelers, H.V.M., Sleutels, T.H.J.A., Jeremiasse, A.W. Rozendal, R.A., 2008. Microbial electrolysis cells for high yield hydrogen gas production from organic matter. Environ. Sci. Technol. 42 (23), 8630-8640.

Lojou, E., Durand, M.C., Dolla, A., Bianco, P., 2002. Hydrogenase activity control at Desulfovibrio vulgaris cell-coated carbon electrodes: biochemical and chemical factors influencing the mediated bioelectrocatalysis. Electroanalysis 14 (13), 913-922.

Lovley, D.R., 2001. Bioremediation. Anaerobes to the rescue. Science 293 (5534), 1444-1446.

Loy, A., Maixner, F., Wagner, M., Horn, M., 2007. ProbeBase - an online resource for rRNA-targeted oligonucleotide probes: new features 2007. Nucleic Acids Res. 35 (Database issue), D800-D804.

Marsili, E., Baron, D.B., Shikhare, I.D., Coursolle, D., Gralnick, J.A., Bond, D.R., 2008 Shewanella secretes flavins that mediate extracellular electron transfer. Proc. Natl. Acad. Sci. USA 105 (10), 3968-3973.

Maymo-Gatell, X., Chien, Y., Gossett, J.M., Zinder, S.H., 1997. Isolation of a bacterium that reductively dechlorinates tetrachloroethene to ethene. Science 276 (5318), 1568-1571.

Nonaka, H., Keresztes, G., Shinoda, Y., Ikenaga, Y., Abe, M., Naito, K., Inatomi, K., Furukawa, K., Inui, M., Yukawa, H., 2006. Complete genome sequence of the dehalorespiring bacterium Desulfitobacterium hafniense Y51 and comparison with Dehalococcoides ethenogenes 195. J. Bacteriol. 188 (6), 2262-2274.

Rabaey, K., Keller, J., 2008. Microbial fuel cell cathodes: from bottleneck to prime opportunity? Water Sci. Technol. 57 (5), 655-659.

Rabaey, K., Verstraete, W., 2005. Microbial fuel cells: novel biotechnology for energy generation. Trends Biotechnol. 23 (6), 291-298.

Rosenbaum, M., Aulenta, F., Villano, M., Angenent, L.T., 2011. Cathodes as electron donors for microbial metabolism: which extracellular electron transfer mechanisms are involved? Bioresour. Technol. 102 (1), 324-333.

Rossetti, S., Aulenta, F., Majone, M., Crocetti, G., Tandoi, V., 2008. Structure analysis and performance of a microbial community from a contaminated aquifer involved in the complete reductive dechlorination of 1,1,2,2-tetrachloroethane to ethene. Biotechnol. Bioeng. 100 (2), 240-249.

Rozendal, R.A., Jeremiasse, A.W., Hamelers, H.V., Buisman, C.J., 2008. Hydrogen production with a microbial biocathode. Environ. Sci. Technol. 42 (2), 629-634

Selembo, P.A., Merrill, M.D., Logan, B.E., 2009. The use of stainless steel and nickel alloys as low-cost cathodes in microbial electrolysis cells. J. Power Sources 190 (2), 271-278. 
Seshadri, R., Adrian, L., Fouts, D.E., Eisen, J.A., Phillippy, A.M., Methe, B.A., Ward, N.L. Nelson, W.C., Deboy, R.T., Khouri, H.M., Kolonay, J.F., Dodson, R.J., Daugherty, S.C., Brinkac, L.M., Sullivan, S.A., Madupu, R., Nelson, K.E., Kang, K.H., Impraim, M., Tran, K., Robinson, J.M., Forberger, H.A., Fraser, C.M., Zinder, S.H., Heidelberg, J.F., 2005. Genome sequence of the PCE-dechlorinating bacterium Dehalococcoides ethenogenes. Science 307 (5706), 105-108.

Tartakovsky, B., Manuel, M.F., Wang, H., Guiot, S.R., 2009. High rate membrane-less microbial electrolysis cell for continuous hydrogen production. Int. J. Hydrogen Energy 34 (2), 672-677.
Turner, J.A., 2004. Sustainable hydrogen production. Science 305 (5686), 972-974. Vincent, K.A., Li, X., Blanford, C.F., Belsey, N.A., Weiner, J.H., Armstrong, F.A., 2007. Enzymatic catalysis on conducting graphite particles. Nat. Chem. Biol. 3 (12), $761-762$.

Zeikus, J.G., 1977. The biology of methanogenic bacteria. Bacteriol. Rev. 41 (2), 514541.

Zeng, K., Zhang, D.K., 2010. Recent progress in alkaline water electrolysis for hydrogen production and applications. Prog. Energy Combust. Sci. 36 (3), 307326. 